\title{
On Translating Artistic Form of Ironical Style in Lu Xun's Fiction
}

\author{
Yikuan Yang $^{1}$ \\ ${ }^{1}$ School of Foreign Languages and Literature, Beijing Normal University, Beijing, China \\ Correspondence: Yikuan Yang, School of Foreign Languages and Literature, Beijing Normal University, Beijing, \\ China. Tel: 86-185-1086-3069. E-mail: yangyikuan87@163.com
}

Received: March 18, 2018 Accepted: September 12, 2018 Online Published: September 14, 2018

doi: 10.5539/elt.v11n10p66 URL: http://doi.org/10.5539/elt.v11n10p66

\begin{abstract}
In response to an age of turmoil and oppression, Lu Xun's fiction features irony and it is manifested in artistic form which should be retained in English translation to achieve equivalence. Failure to do so would weaken or lose the ironical effect intended by Lu Xun and result in Western readers' inclination to neglect historical and social contexts of his time and to miss the thematic significance of his works. In view of inadequate research in this, the thesis explores the artistic form of ironical style in Lu Xun's fiction, the preservation of form and ironical effect in William A. Lyell's, the YANGs' and Julia Lovell's English translations and their strategies of compensation for inevitable loss due to cultural and linguistic differences between Chinese and English. However, over-compensation is to be avoided, for it would spoil the delicacy of irony, and so is under-compensation which would reduce the artistic value of the form of irony and cut the ironical effect. Sometimes even if compensation is applied, the ironical effect could hardly be kept intact. Behind Lu Xun's ironical style is his concern for the future of China and the Chinese people, his indignation against oppression, his disappointment at some people's numbness and stupidity and his sorrow toward the failure of the Xinhai Revolution. Translators should bear this in mind when rendering his ironical style from Chinese into English, otherwise they will miss the thematic significance of Lu Xun's fiction.
\end{abstract}

Keywords: Lu Xun's fiction, ironical style, artistic form, ironical effect, English translation

\section{Introduction}

QIAN Liqun (1999: 60), a professor with Peking University, notes, that much attention has been given to the study of Lu Xun's thought and the impact of his fiction on society and far less to the art of his language, and believes that "the key to $\mathrm{Lu}$ Xun's studies is to grasp his artistic thought and creativity in language form". Harvard professor Patrick Hanan (1974: 53) perceives Lu Xun's fiction as "the most powerfully expressive art in modern Chinese literature" and attributes it to the combination of "a venture in technique, a fresh try at the perfect matching of subject and form, and the quality of the emotions and judgments behind his work".

Both QIAN Liqun's comment “peculiar creativity in language form" and Hanan's "perfect matching of subject and form" on Lu Xun's fiction point to the style of his works. Hanan (1974: 96) observes that Lu Xun's "irony and detachment are a psychological and artistic necessity for a writer gripped by moral rage, didactic passion and private conscience" which are expressed in "a valid artistic form", and holds that Lu Xun was "almost alone among the writers of his generation in grasping irony and the mask".

Ironical style threads through Lu Xun's fiction. Style encompasses content and form, and Lu Xun, to express irony, employs artistic form which its English translation should preserve to achieve equivalence. Failure to do so would weaken or lose the ironical effect intended by Lu Xun and result in Western readers' inclination to neglect historical and social contexts of his time and to miss the thematic significance of his works. In view of inadequate research in this, the thesis explores the artistic form of ironical style in Lu Xun's fiction, the preservation of form and ironical effect in William A. Lyell's, the YANGs' and Julia Lovell's English translations and their strategies of compensation for unavoidable loss due to cultural and linguistic differences between Chinese and English.

\section{Irony: Origin, Definition \& Function}

The word "irony" came from Greek "eironeia" which originally referred to the comic character "eiron" who always pretended to be ignorant and yet in the end triumphed over the braggart and stupid "alazon". "Eironeia" first appeared in Plato's Republic and was considered as "a sort of vulgar expression and reproach... sly, 
mocking pretense and deception" (Knox, 1972: 3). "Irony" initially had derogatory sense.

Later, "irony" became a word with neutral connotations. Republic recorded how Socrates used irony in debates. He pretended to be less intelligent than he really was and craved for instructions from his opponent, and then Socrates kept asking questions to reveal the other party's ignorance and make him agree with Socrates. This is termed "Socratic Irony".

Aristotle (1997: 596) in Rhetoric describes irony as a figure of speech, "The speaker wishes to say something but pretends that he does not, or expresses something contrary to facts." To him, irony is used to "blame by praise" or "praise by blame" (Knox, 1972: 4). Cicero expanded the definition of irony from expressing contrary meaning into conveying meanings different from the literal meaning and viewed irony as a disguise in oratory. Besides blame or praise, irony can be used for humorous effects (Quintilian, 1875). The word "irony" was introduced into English in the $15^{\text {th }}$ Century but it's not until $18^{\text {th }}$ Century that it frequently appeared in literary works and daily life (Knox, 1972: 8). Wilson \& Sperber (1992: 55) countered definitions of irony as "saying one thing and meaning the opposite" or "saying one thing and meaning another" by offering the example "When a man is tired of London, he is tired of life" which neither conveys meaning contrary to nor meaning different from the literal meaning but expresses certain emotion and attitude.

\section{Translating Style: Significance and Possibilities}

Style encompasses content and form. The discussion on the translation of style includes the investigation of the translation of form. TONG Qingbing (1994: 90), a professor with Beijing Normal University, defines "style" as a characteristic that reflects the writer's creativity and preference and gives readers aesthetic enjoyment. Western scholar Dryden sees "style" as the writer's "idiosyncratic, delicate thought and its expression" (Lefevere, 1992: 104). According to A Glossary of Literary Terms, "Style has traditionally been defined as the manner of linguistic expression in prose or verse - as how speakers or writers say whatever it is that they say" (Abrams \& Harpham, 2012: 384). From these definitions, we can see that style encompasses content and form and reflects the writer's individuality and creativity. Form is how the writer expresses his thoughts, and content is what he expresses. Form and content are interdependent and constitute the unity of a literary work.

Scholars worldwide attach great importance to retaining in translation the style of the source text. In China, Kumarajiva (344-413) of the Eastern Jin Dynasty (317-420) holds that though meaning is much maintained, the loss of style when translating Buddhism from Sanskrit into Chinese amounts to chewing food to feed others, which would make the food flavorless and lead to disgust (Chen, 1996: 26). In the West, Tytler emphasizes that "The style and manner of writing should be of the same character with that of the original." (Munday, 2008: 27) Nida and Taber (1982: 12) observe that equivalence in translation includes equivalence in both meaning and style. Translation of "style" is so important, then is it translatable?

French naturalist and writer Buffon (1707-1788) (1959: 45) believes not, "Abundant knowledge, exceptional events and novel discoveries cannot guarantee the eternity of any work, because these can be passed on to others and even surpassed with more ingenuity. But if the work is without singular style, talents and elegance, it will be buried. Knowledge, events and discoveries are external, while style is the man himself. Style, therefore, cannot be transposed." His reasoning for the untranslatability of style is that style cannot be separated from its producer (namely, the writer) and his work. Zhou (2006), a master translator of English literature in China, thinks that the style of the target text is influenced by the style of the source text, the translator's individuality, norms of the target language and the social context the translator is in and therefore style is untranslatable.

Other scholars adopt a mild approach toward the translatability of style and avoid absolutism. They air that style is to some extent translatable and partial loss is inevitable. Influenced by the translator's knowledge and thought, disposition and habitual language use, the style of the source text can hardly be kept fully in the target text (Xu, 1992: 84). Different languages reflect different "styles of nationalities" of different countries, so it's quite difficult to reproduce the complete style of the source text in another language (Lao, 1984: 69).

\section{Translatability of Ironical Style and Compensation}

Let's narrow down the translatability of style to the translatability of ironical style. Barbe (1995) believes that the construction and interpretation of irony are determined by culture. Irony serves different purposes in different cultures. In one culture irony may be a "face-saving politeness mechanism" while in another it can be "openly hostile" (Barbe, 1995: 145). "Cultures, speech-communities, a close circle of friends, a married couple, all have mechanisms at their disposal to keep others from understanding, that is, to keep others 'out', and irony is one of these mechanisms" (Barbe, 1995: 146). Besides cultural-specific, irony is also group- and individual-specific (Barbe, 1995: 147), making it hard to translate. But, irony is highly translatable when: 
—participants share or are aware of each other's cultural knowledge

-use similar linguistic realizations of irony

— share same or similar face-saving devices

—use irony for same or similar purpose

-have comparable institutional organizations (justice/political systems, for example)

(Barbe, 1995: 167)

Barbe's five criteria suggest that the more the two languages and cultures have in common, the more translatable irony is. But there are other factors which should also be considered, e.g., personal knowledge and situational knowledge shared by the writer and translator. Barbe's research is based on German and English which have much more similarities than Chinese and English. The translatability of ironical style from Chinese into English is more problematic.

Apart from discussing when irony is highly translatable, Barbe (1995) also contributes to strategies for translating ironical style:

-reproduce the same irony

—replace the SL-image with an appropriate TL-image

—add a potential irony marker (usually a modal particle)

—add a description

-keep SL-idiosyncrasy (such as writing conventions)

(Barbe, 1995: 166-167)

Far more differences exist between Chinese and English than those between European languages. The greater loss of ironical style in Chinese-English translation calls for compensation. Harvey (1995: 78-82) proposes a descriptive framework for compensation along three axes: 1) the typological axis "identifies instances of compensation", including stylistic and stylistic-systemic compensation; 2) the correspondence axis "establishes the linguistic relationship" and "describes the degree of linguistic correspondence", including direct and analogical correspondence and non-correspondence; 3 ) the topographical axis "concerns the respective location of the effect lost in the source text and compensated for in the target text", including parallel, contiguous, displaced and generalized.

To compensate for unavoidable loss of artistic form in translating the ironical style of Lu Xun's fiction, Lyell, the Yangs and Lovell either replace artistic forms exclusive to the source language with those consistent with the norm of the target language, or make explicit cultural information, or add a footnote to achieve the same ironical effect.

\section{English Translation of Artistic Form of Ironical Style in Lu Xun's Fiction}

Lu Xun, by way of irony, criticizes class oppression and exploitation and some people's ignorance and numbness, reveals problems of the Xinhai Revolution (1911) and voices his concerns and worries toward the future of China and the Chinese people. The ironical style is expressed in artistic form, such as parody, understatement, assonance, metaphor, oxymoron, reduplication, onomatopoeia, overstatement, contrast between classical Chinese and modern vernacular Chinese and blending English into Chinese text. MAO Dun (1896-1981), the first chairman of the China Writers Association and the first Minister of Culture of the P.R.C., stresses the importance of retaining in translation the artistic form of the source text, "Understanding the writer's thought is important, and appreciating the artistic expression in the original work is far more important" (Chen, 1996: 248).

\subsection{Parody}

Parody is "the imitative use of the words, style, attitude, tone and ideas of an author in such a way as to make them ridiculous... There has to be a subtle balance between close resemblance to the 'original' and a deliberate distortion of its principal characteristics" (Cuddon, 2013: 514). The original is often something serious.

Source text: 后来这终于从浅闱传进深围里去了。(“阿 Q 正传”)
Lyell's translation: News of all this excitement eventually made its way from the shallows of
ordinary village bedrooms into the depths of the Zhao and Qian boudoirs...
The YANGs' translation: This news later spread from the poor households to the rich ones...
Lovell's translation: Eventually, the news seeped into even the great boudoirs of the village.

In ancient China “深闺” (“深” means “deep”, “闺” “boudoir”) refers to rich women’s bedrooms, and because the house of rich family has many rooms and women's bedrooms are in the innermost of the house, it is “深” (deep). 
Lu Xun imitates the structure of “深闺” and creates a new word “浅闺” to refer to women’s bedrooms of ordinary families.

“这” refers to the news of Ah Q "getting” some goods for sale in Weizhuang Village. Seventh Sister Zou first bought from him a skirt, and when the wife of the wealthy Old Master Zhao heard the news, she wanted to buy a sleeveless fur jacket and invited Ah Q to come to her place to talk about the deal. Ah Q then gained respect, a sharp contrast to how people slighted and beat him before. How ironical!

Lu Xun, on the surface, writes about the news passed from “浅闺” to “深闺”, but in fact alludes to the influence of the Xinhai Revolution which went deeper and deeper, from ordinary families to rich ones. Ah Q's soaring in social status mirrored the change in class stratification engendered by the Xinhai Revolution. When Ah Q became connected with revolution, villagers around abandoned their usual contempt and started to respect him in consideration of their own interest. The route from “浅闺” to “深闺” is a miniature of the development of the Xinhai Revolution and its impact. English translation should preserve this artistic form of the source text.

Lyell does not use parody, but employs explicitation for compensation to explain to readers the meaning of “浅 闺” and “深闺”. The compensation in the target text is at the same place as the effect lost in the source text, and it's a parallel relationship on the topographical axis according to Harvey's (1995: 82) classification. Although no compensation is found on the typological axis and correspondence axis, he retains the contrast between “shallows" (meaning “浅”) and “depths" (meaning “深”), which shows the progression of the news as the source text does and thus achieves ironical effect and gives prominence to the thematic significance of the novel.

The YANGs' translation "poor households" and "rich ones" abandons the meaning of “闺房” (boudoir), which neglects Ah Q's relation to “闺”. He once did odd jobs in Old Master Zhao's house and this enabled him to have access to “浅闺” and show his love toward Amah Wu. Such act was seen as something outrageous and unimaginable. Ah Q was beaten and kicked out. He even did not have the right of love. “闺” is closely linked to the theme of the novel. Feudal ethics imposed strict restrictions on the relation between male and female, but were easily bent and abandoned by Mrs. Zhao's want of a cheap secondhand fur jacket from Ah Q, at which irony is directed. The YANGs' translation erases this layer of thematic meaning of the novel and loses ironical effect.

Lovell's translation "great boudoirs" shows no sign of parody but "even" describes the progression of the news, and thus retains some degree of the ironical effect.

\subsection{Assonance \& Understatement}

Assonance is the resemblance in the sounds of words or syllables. Understatement "deliberately represents something as very much less in magnitude or importance than it really is, or is ordinarily considered to be" (Abrams \& Harpham, 2012: 167). Understatement, when coupled with assonance, reinforces the irony.

Source text: 未庄人都惊服，说这是柿油党的顶子，抵得一个翰林...... (“阿 Q 正传”)
Lyell's translation: Everyone said it was the symbol of the "Persimmon Oil Party" and
worth at least an Imperial Academy Button.
The YANGs' translation: All the Weizhuang villagers were overawed, and said that this was
the badge of the Persimmon Oil Party, equivalent to the rank of a Han Lin.
Lovell's translation: This, it was put about with gasps of admiration, was the insignia of the
Persimmon Oil Party. Their local scholar was now equal in rank to a member of the
imperial academy!

“柿油党” is the assonance of “自由党” (“ziyoudang”, meaning “liberal party”). Lu Xun understates “自由党” as “柿油党” (“柿” means “persimmon”, a kind of fruit) to target irony at stupid Weizhuang villagers who were opportunistic toward the revolution.

Lyell's, the YANGs' and Lovell's translations are all "Persimmon Oil Party" which can be seen as understatements and have ironical tones, but no connection exists between "Persimmon Oil Party" and "liberal party" because there's no linkage in sound. The artistic form of ironical style of the source text is only partially retained, and ironical effect greatly reduced. The thematic significance of the novel is weakened.

Lovell, however, compensates for the loss by adding a footnote "In Chinese, 'freedom', ziyou, sounds very much like 'persimmon oil', shiyou; an understandable error of hearing, therefore, by the good burghers of Weizhuang." Her strategy falls into the category of displaced compensation in which "the instance of compensation in the target text is a long distance from the source text loss" (Harvey, 1995: 83). No compensation is found on the 
typological axis and correspondence axis. Readers need to refer to the footnote to get the ironical clue. Ironical effect is partially retained, but her footnoted translation is more closely connected with the theme of the novel.

\subsection{Metaphor}

"Metaphor, the most important and widespread figure of speech, in which one thing, idea, or action is referred to by a word or expression normally denoting another thing, idea, or action, so as to suggest some common quality shared by the two. In metaphor, this resemblance is assumed as an imaginary identity rather than directly stated as a comparison." (Baldick, 2001: 153)

Source text: 这一场“龙虎斗”似乎并无胜败...... (“阿 Q 正传”)
Lyell's translation: So it would seem that there was no victory or defeat in the epic battle
that was mounted by these two renowned warriors...
The YANGs' translation: This epic struggle had apparently ended in neither victory nor
defeat...
Lovell's translation: There was a certain lack of clarity and closure about this particular
battle between the dragon and tiger of Weizhuang.

“龙虎斗” (“龙” means “dragon”, “虎” tiger, “斗” fight/battle) is the name of a drama in China. It's a story about HUYAN Zan's just revenge against OUYANG Fang who set up a trap and was responsible for General HUYAN Shouting's undeserved sentence to death by Emperor ZHAO Kuangyin (927-976) of the Song Dynasty. The story reflects the cry of the Song people for justice against the cunning courtier OUYANG Fang and people's courage against injustice and power. Lu Xun uses “龙虎斗” to denote the fight between Ah Q and Young D who were both skinny, weak and empty-headed. Such contrast expresses irony. On the surface, the irony ridicules Ah Q and Young D, but more is to be unveiled if readers go deeper. The metaphor here alludes to some people who watched the revolution as the drama “龙虎斗” and when it's over, went back home as usual and thought about it no more.

Lyell's and the YANGs' translations "epic battle" and "epic struggle" are overstatements to compensate for the loss of metaphor, but they lack vividness. The target text reader cannot link "epic battle/struggle" with the story behind the drama “龙虎斗”. The deeper ironical effect is lost.

Lovell's translation "battle between the dragon and tiger" corresponds to the source text, but readers unfamiliar with Chinese culture may not get the ironical clue. All these three translations miss the theme of the novel which reveals some people's taking the revolution lightly and watching it as a drama.

\subsection{Oxymoron}

Oxymoron "combines incongruous and apparently contradictory words and meanings for a special effect" (Cuddon, 2013: 504). It seems illogical and absurd on the surface but understandable in a way that makes sense.

Source text: 他们没有杀人的罪名, 又偿了心愿, 自然都欢天喜地的发出一种鸣鸣咽咽的 笑声。(“狂人日记”)

Lyell's translation: They wouldn't be guilty of murder, and yet they'd still get everything they're after. Why, they'd be so beside themselves with joy, they'd sob with laughter.

The YANGs' translation: ...they can enjoy their hearts' desire without being blamed for murder. Naturally that delights them and sets them roaring with laughter.

Lovell's translation: ...they will achieve their heart's desire without staining their hands with my blood - I hear their gasps of jubilant laughter already.

“鸣鸣咽咽” (sound of weeping) and “笑声” (sound of laughter) contradict in meaning, but is interpretable. “笑 声” refers to their delight in eating people. “鸣鸣咽咽” indicates that although they ate people, they pretended to be sympathetic and sad. Oxymoron creates irony toward the eater and feudal ethics.

Lyell's translation retains oxymoron and achieves the same ironical effect as the source text. In the YANGs' and Lovell's translations, oxymoron are abandoned and English equivalence of “鸣鸣咽咽” omitted. Both form and content are lost, and so are ironical effect and the theme of the novel which reveals the hypocrisy of feudal ethics.

\subsection{Reduplication \& Onomatopoeia}

Reduplication refers to a word with a reduplicated element. Onomatopoeia "designates a word, or a combination of words, whose sound seems to duplicate the sound it denotes" (Abrams \& Harpham, 2012: 264). Reduplication, 
when coupled with onomatopoeia, reinforces ironical effect.

Source text: 他便爬上这矮墙去, 扯着何首乌藤, 但泥土仍然籁籁的掉, 阿 Q 的脚也索
索的抖...... (“阿 Q 正传”)
Lyell's translation: ...he grabbed the blackhair vines that covered the wall and started to
climb. Everyplace he managed to get a toehold, the dirt of the wall crumbled and whooshed
down through the leaves while the trembling of his feet rustled the vines.
The YANGs' translation: ... he scrambled on to the low wall, holding on to some milkwort.
The mud wall started crumbling, and Ah Q shook with fear...
Lovell's translation: He then set about scaling the garden wall, hauling himself up on a bunch
of knotweed. As the surface of the wall crumbled, Ah-Q's feet began to tremble beneath
him...

“籁籁” (pinyin “sù sù”) 和“索索” (pinyin “suǒ suǒ”) are onomatopoeic and reduplicated words to express irony toward Ah Q's hurry-scurry out of nervousness when stealing vegetables.

Lyell's translation "crumbled" and "rustled" and Lovell's translation "crumbled" and "tremble" are onomatopoeia. They do not use reduplication, for reduplication is uncommon and unnatural according to the norm of the English language. To compensate for the loss of this artistic form, they utilize rhyme /bal/. On the typological axis, it's stylistic compensation, "where the effects achieved in the source and target texts are text-specific and contribute uniquely to the color, tone and register of that particular text" (Harvey, 1995: 78); on the correspondence axis, it's analogical correspondence, "where the device used in the target text to compensate for a lost source text effect is derived from the same linguistic repertoire as that used in the source text, without being of an identical type" (Harvey, 1995: 81); on the topographical axis, it's parallel compensation. The ironical effect is as intense as the source text.

The YANGs' translation "crumbling" is onomatopoeia, but not reduplication. This loss of artistic form he does not compensate for. He renders “索索” into "fear", abandoning the two artistic forms of the source text. Much ironical effect is gone.

\subsection{Overstatement \& Idiom With Four Chinese Characters}

Overstatement states in exaggerated terms. Though some opinions equate overstatement with hyperbole, differences exist between these two terms. In hyperbole, the literal intention is the same as the writer's true intention, while in overstatement, the literal intention is contrary to or different from the writer's true intention, which helps form irony. Lu Xun often uses formal and serious words to describe trivial things and events. His true intention behind his elevation of these trifles is to belittle them.

Source text: 七斤虽然住在农村, 却早有些飞黄腾达的意思...... (“风波”)

Lyell's translation: Although Sevenpounder lived in a country village, his family had early on showed promise of scaling the ladder of prestige.

The YANGs' translation: Although a villager, Sevenpounder had always wanted to better himself.

Lovell's translation: Although Seven-Pounds still lived in the old family village, he was a man going places.

“飞黄腾达” is an idiom with four characters (common in Chinese) which means speedy elevation of rank in the government, but Sevenpounder was just a villager who led a slightly better life than other villagers by poling the boat and was respected only for his knowing a little bit more by hearing some news from town. The news he got was merely a source of conversation for villagers and its authenticity was highly questionable. Lu Xun uses "飞 黄腾达” to describe Sevenpounder, which on the surface is to praise and elevate but in fact is to direct irony at his self-complacence and villagers' stupidity. “飞黄腾达” also foreshadowed the "storm” of cutting off men's queues.

The English language does not have idioms with four characters as Chinese does, and to compensate for the loss of this form, Lyell uses metaphor "scaling the ladder of prestige". Moreover, "promise" and "prestige" forms alliteration. On the typological axis, it is stylistic-systemic compensation, "where the effects have a stylistic value where they occur in the text, but these draw upon part of the conventional systemic resources of the language" (Harvey, 1995: 78); on the correspondence axis, it's analogical correspondence; on the topographical axis, parallel relationship exists. Even if with compensation, Lyell's translation is not as vivid as “飞黄腾达” 
since the latter stresses rapidity and radical change, so the ironical effect is reduced in the target text.

The YANGs' translation "better" loses, both in content and form, the ironical style of the source text. "Better" may result in the reader's understanding of Sevenpounder as a man aspiring for self-improvement, which runs contrary to what he really was in the source text. Ironical effect is no longer present. Lovell's translation "going place" means “to become successful (Note 1)", but “飞黄腾达” is far beyond that. Though her translation is also an overstatement, it lacks vividness and artistic form. Ironical effect is greatly reduced.

\subsection{Contrast Between Classical Chinese and Modern Vernacular Chinese}

$\mathrm{Lu}$ Xun uses mostly modern vernacular Chinese in his fiction. If both classical Chinese and modern vernacular Chinese appear in one fiction, the sharp contrast would reinforce what the writer wishes to express.

Source text (from “狂人日记”):
Front matter: 某君昆仲, 今隐其名, 皆余昔日在中学时良友; 分隔多年, 消息渐阔......
Main text: 今天晚上, 很好的月光。我不见他, 已是三十多年; 今天见了，精神分
外爽快......
Lyell's translation of the front matter: There was once a pair of male siblings whose
actual names I beg your indulgence to withhold. Suffice it to say that we three were
boon companions during our school years. Subsequently, circumstances contrived to
rend us asunder so that we were gradually bereft of knowledge regarding each other's
activities.
Lyell's translation of the main text: Moonlight's really nice tonight. Haven't seen it in
over thirty years.
The YANGs' translation of the front matter: Two brothers, whose names I need not
mention here, were both good friends of mine in high school; but after a separation of
many years we gradually lost touch.
The YANGs' translation of the main text: Tonight the moon is very bright. I have not seen
it for over thirty years...
Lovell's translation of the front matter: At school I had been close friends with two
brothers whose names I will omit to mention here. As the years went by after we
graduated, however, we gradually lost touch.
Lovell's translation of the main text: The moon is bright tonight. I had not seen it for
thirty years; the sight of it today was extraordinarily refreshing. Tonight, I realized I have
spent the past thirty years or more in a state of dream...

The main text of “狂人日记” is written in modern vernacular Chinese, but the front matter is in classical Chinese which is formal and conspicuous. The front matter tells readers that it's written by a madman, so the diary was of course nonsensical. But the madman had a sharp mind, for he discovered, as the main text of his diary tells us, the astounding phenomenon of "eating people", and cried for actions to "save the children". The front matter and the main text contradict and it's revealed by the contrast between classical Chinese and modern vernacular Chinese. The front matter does not aim at helping readers understand the main text of the diary, but to subvert and dispel, by which Lu Xun directs irony at feudal ethics which taught people to "eat people" and voices concerns and worries toward the future of China and the Chinese people. English translations of the front matter and the main text of the diary should preserve the same contrast.

Lyell's translation of the front matter features formal language and the main text colloquial. The contrast and ironical effect are retained. The YANGs' and Lovell's translations of the two parts are both in informal language and fail to preserve the contrast, resulting in the loss of ironical effect and the thematic meaning of the novel which criticizes the cruelty and hypocrisy of feudal ethics.

\subsection{Blending English Into Chinese Text}

The appearance of English words in Chinese fiction produces incongruity and serves Lu Xun's purpose for ironical effect.

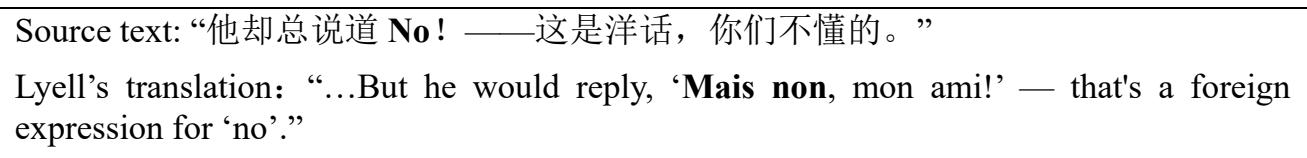




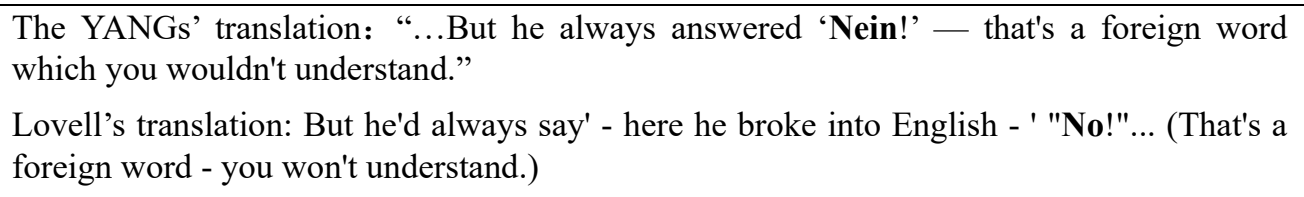

The source text is about “假洋鬼子” (“Fake Foreign Devil”, Lyell’s translation) bragging about his visiting Brother Hong and having planned revolution with Brother Hong. The unexpected and sudden appearance of the English word "no" in a novel written in Chinese disconnects it from the novel, the main part, and this alludes to the disconnection between the revolutionaries and the masses. “这是洋话, 你们不懂的” (“that's a foreign expression for "no"', Lyell's translation) further implies that the revolutionaries distanced themselves from the masses, which accounted for the failure of the revolution and at which $\mathrm{Lu}$ Xun is ironical.

Both Lyell and the YANGs notice Lu Xun's intention of blending English word into Chinese fiction and respectively render "No" into French expression "mais non" and German "Nein" which both produce incongruity in the English target text to achieve ironical effect. Lovell's translation "No" fails to create incongruity in the English target text and loses ironical effect. Without incongruity as the clue, readers cannot see the superiority (showing that they know more by speaking out a foreign word) the revolutionaries felt which distanced themselves from the masses and led to the failure of the revolution. Her translation misses the thematic significance of the novel.

\section{Conclusion}

This thesis has discussed eight artistic forms of the ironical style in $\mathrm{Lu}$ Xun's fiction and their English translations by Lyell, the YANGs and Lovell. In a few cases English and Chinese have the same expression for ironical effect and compensation is not needed, but for most of the time, the great differences between the two languages call for compensation due to certain loss. Most compensations, on the typological axis, are stylistic, because the source text expresses irony mainly by figure of speech as regards the eight examples in the thesis; on the correspondence axis, are analogical and not direct correspondence, because English differs greatly from Chinese in linguistic repertoire; on the topographical axis, are parallel (footnote is displaced compensation, as its name suggests), because this thesis mainly discusses artistic form on lexical level instead of syntactic level. However, over-compensation is to be avoided, for it would spoil the delicacy of irony, and so is under-compensation which would reduce the artistic value of the form of irony and cut the ironical effect. Sometimes even if compensation is applied, ironical effect could hardly be kept intact. In certain cases although the translation denotes the same thing as the source text and achieves equivalence on the surface, the deep thematic meaning associated with historical context is lost.

\section{Acknowledgements}

This study is funded by the project "The Construction of Cloud Platforms of English Translations of Chinese Ancient Books and Records and Translation Studies" (17AYY012) which is granted by China's National Office for Philosophy and Social Sciences.

\section{References}

Abrams, M. H., \& Harpham, G. (2012). A Glossary of Literary Terms (10th ed.). Boston: Cengage Learning. Aristotle. (1997). Rhetoric. Complete Works of Aristotle (Vol. 9). Beijing: China Renmin University Press.

Baldick, C. (2001). The Concise Oxford Dictionary of Literary Terms. New York: Oxford University Press.

Barbe, K. (1995). Irony in Context. Amsterdam: J. Benjamins. https://doi.org/10.1075/pbns.34

Buffon. (1959). On Style. In Translation. Beijing: People's Literature Publishing House.

Chen, F. K. (1996). Zhongguo Yixue Lilun Shigao (The History of Translation Theories in China). Shanghai: Shanghai Foreign Language Education Press.

Cuddon, J. A. (2013). A Dictionary of Literary Terms and Literary Theory (5th ed.). Chichester: Wiley-Blackwell.

Hanan, P. (1974). The technique of Lu Hsün's fiction. Harvard Journal of Asiatic Studies, 34, 53-96. https://doi.org/10.2307/2718696

Harvey, K. (1995). A descriptive framework for compensation. The Translator, 1, 65-86. https://doi.org/10.1080/ 13556509.1995.10798950

Knox, N. (1972). On the classification of ironies. Modern Philology, 70, 53-62. https://doi.org/10.1086/390377 
Lao, S. (1984). Chukouchengzhang (On Writing). Beijing: People's Literature Publishing House.

Lefevere, A. (1992). Translating Literature: Practice and Theory in a Comparative Literature Context. New York: Modern Language Association of America.

Lu, X. (1990). Diary of a Madman and Other Stories. Hawaii: University of Hawaii Press.

Lu, X. (2009). The Real Story of Ah-Q and Other Tales of China: The Complete Fiction of Lu Xun. London: Penguin Group.

Lu, X. (2010). Call to Arms. Beijing: Foreign Languages Press.

Lu, X. (2010). Wandering. Beijing: Foreign Languages Press.

Munday, J. (2008). Introducing Translation Studies (2nd ed.). London and New York: Routledge.

Nida, E., \& Taber, C. (1982). The Theory and Practice of Translation. Leiden: Brill Academic Pub.

Qian, L. Q. (1999). Lu Xun Xiaoshuo De Xingshi Yiyi Xu (Preface to The Formal Meaning of Lu Xun's Fiction). Luxun Research Monthly, 07, 58-60.

Quintilian. (1875). Quintilian's Institute of Oratory, or Education of an Orator. London: Bell.

Tong, Q. B. (1994). Wenti Yu Wenti De Chuangzao (Stylistics and the Creation of Stylistics). Kunming: Yunan People's Publishing House.

Wilson, D., \& Sperber, D. (1992). On verbal irony. Lingua, 87, 53-76. https://doi.org/10.1016/0024-3841(92)90 025-E

Xu, J. (1992). Wenxuefanyipiping Yanjiu (Critics of Literary Translation). Nanjing: Yilin Press.

Zhou, X. L. (2006). ZHOU Xuliang Wenji (Literature of Zhou Xuliang). Shanghai: Shanghai Translation Publishing House.

Note 1. https://www.collinsdictionary.com/dictionary/english/go-places

\section{Copyrights}

Copyright for this article is retained by the author(s), with first publication rights granted to the journal.

This is an open-access article distributed under the terms and conditions of the Creative Commons Attribution license (http://creativecommons.org/licenses/by/4.0/). 